\title{
Evidence, Engagement, and Technology: Themes of and the State of Primary Care Practice-based Network Research
}

\author{
Donald E. Nease, Jr., MD
}

Practice-based research supported by practice-based research network (PBRN) infrastructure has historically provided an important method for challenging guidelines and evidence arising from secondary and tertiary care settings. This sample of current practice-based research in this issue of the JABFM provides an opportunity to ask whether practice-based research continues to address questions relevant to primary care practices and clinicians and whether a PBRN infrastructure is instrumental to maintaining the relevance and feasibility of practice-based research. Based on this issue's articles, the current state of practice-based research seems to be good, at face value addressing relevant issues for primary care practices. Less clear is the degree to which PBRN infrastructures and relationships informed the questions asked and facilitated the implementation of the studies presented. Practice-based research-related articles that routinely report about how study questions arose-from practices and their clinicians, staff and communities, or elsewhere-could help directly answer questions of relevance. In addition, reporting how practices are recruited to practice-based research studies could inform the degree to which ongoing relationships central to PBRNs facilitate the recruitment and conduct of practice-based research. (J Am Board Fam Med 2016;29:521-524.)

The occasion of the annual $\mathcal{F A B F M}$ issue dedicated to practice-based research provides an excellent opportunity to review the current state of practicebased research and practice-based research network (PBRN) activity in the United States. PBRNs began in the 1970 s as a reaction to the dominant research paradigm of the time, which was largely research conducted in academic health centers, reflecting little of the populations and settings where the majority of care tended to be delivered. PBRNs were a manifestation of the counterculture theme identified within Family Medicine by Gayle Stephens $^{1}$ and in Pediatrics by Fitzhugh Mullen's White Coat, Clenched Fist, ${ }^{2}$ and they largely addressed questions that arose from their constitu-

From the Department of Family Medicine, University of Colorado-Denver School of Medicine, Aurora.

Funding: none.

Conflict of interest: none declared.

Corresponding author: Donald E. Nease, Jr., MD, Department of Family Medicine, University of Colorado-Denver School of Medicine, 12631 East, 17th Avenue, Mail Stop F-496, Academic Office 1, Aurora, CO 80045 (E-mail: Donald.Nease@ucdenver.edu). ents, challenging the conventional wisdom. Funding was scarce, yet the important work done by PBRNs changed the practice of medicine. Routine computed tomography scans for headaches and routine antibiotics for otitis media were just $2 \mathrm{dog}$ mas that were successfully challenged by enterprising PBRN research. ${ }^{3-5}$

Some might say that little about this dominant paradigm has changed today. ${ }^{6}$ Most federally funded research dollars still go toward academic health center research, yet PBRNs have multiplied across the country with an amazing diversity of structures and missions. As of this writing, the Agency for Healthcare Research and Quality's PBRN registry (https://pbrn.ahrq.gov/pbrnregistry) lists 173 active PBRNs covering nearly all 50 states and representing a variety of disciplines. Our 2016 North American Primary Care Research Group (NAPCRG) PBRN Conference had 196 registrants, and over 50 have enrolled in the second cohort of the Practice-Based Research Methods Certificate Program hosted by the Case Western Reserve University PBRN Resource Center and 
funded by the Agency for Healthcare Research and Quality. The state of PBRN research seems to be improving.

Our focus in this issue is on practice-based research done in primary care-based PBRNs, which still represent the largest proportion of PBRNs. It is worth asking, to what extent does current practice-based research, as represented by this sample, continue to address questions that come from, and are best answered by, gathering data at the practice level, supported by a PBRN infrastructure? In addition, in a health care context where few practices are independent, it is important to understand whether a PBRN infrastructure is important to generate relevant questions and facilitate the recruitment and implementation of practice-based research. Within this issue are 10 articles addressing a variety of topics. The themes include technology application in primary care, implementation of evidence, and patient engagement, all 3 of which speak directly to important and relevant topics for today's primary care practices.

Beginning with implementation of evidence, 3 studies directly address this issue. Mader et $\mathrm{al}^{7}$ examined whether academic detailing and practice facilitation are effective methods for increasing cancer screening rates. Lipman and Aspy ${ }^{8}$ studied the effectiveness of local learning collaboratives as a method for diffusing current chronic kidney disease guidelines into practices. Johnson et $\mathrm{al}^{9}$ developed and evaluated an approach for practices to make decisions about which guidelines to implement. All 3 studies are examples of research that is well suited to PBRNs, not necessarily because of their sample sizes but for the ground-level knowledge about the everyday delivery of primary care. These 3 studies also highlight how much of PBRN work today concerns the study of methods to move evidence into practice rather than challenging the validity of accepted evidence.

Patient and community engagement is a relatively new theme in PBRN research, although these approaches have much in common with PBRN methods, as has been previously identified by others. ${ }^{10}$ Rapp and Pascoe ${ }^{11}$ examined the concept of partnership, soliciting views from both patients and practices. The complex connotations behind a seemingly straightforward concept of partnership are striking, and this work represents an important step toward helping practices identify how their own patient populations view partner- ship. Cole and Keppel ${ }^{12}$ studied patients' willingness to participate in comprehensive weight loss programs, importantly addressing a problem and service for which practices can now receive reimbursement but of which only a few take advantage. This study affirms that a majority of patients are open to receiving weight loss help from their primary care practice. Bridging the themes of patient engagement and technology, Careyva et $\mathrm{al}^{13}$ researched the degree to which technology-based patient engagement tools are being used in PBRNs around the country, finding that information technology support remains a barrier to the broad study and implementation of these tools. Also bridging the engagement and technology themes, Wallace et $\mathrm{al}^{14}$ studied the uptake of electronic health record (EHR)-based patient portals within practices serving disadvantaged populations, finding that uptake, while low overall, was especially low in men, older adults, and racial and ethnic minority adults, suggesting the need to develop strategies to target these individuals. These 3 studies, while quite different in their questions and methods, highlight how patients' perspectives and their direct participation in care are becoming more and more relevant to primary care.

Finally, 3 studies deal directly with the use of technology in primary care. Litvin et $\mathrm{a}^{15}$ researched the impact of embedding chronic kidney disease decision support tools in an EHR, finding that the technology resulted in modest but significant gains in some screening and management behaviors, but that organizational and attitudinal barriers often stood in the way of more significant improvements. Dexter et $\mathrm{al}^{16}$ examined whether EHR-based patient portal use reduced telephone calls, with the surprising finding that as practices implemented the patient portal and patients began to use it, calls actually increased. Both of these studies, as well as that by Wallace et al, ${ }^{14}$ demonstrate how EHR-based PBRNs that use a common technology can be used to answer important technology use questions. Finally, Chung et a ${ }^{17}$ evaluated the implementation of a blood pressure kiosk in one practice, gaining important knowledge on workflow, acceptance, and outcomes from that single practice. While important in advancing knowledge about the implementation of a new technology from a "real-world" practice, more is clearly needed from a larger sample. 
Finally, Gaglioti et $\mathrm{al}^{18}$ contribute a very stimulating commentary suggesting that PBRN researchers adopt an engagement strategy for increasing awareness, support, and funding for PBRN research at local, regional, and national levels. This brings together threads that have been a historic strength of PBRN work: relationship building, sourcing ideas from the ground level, and seeking practical solutions to real problems.

I return to the question posed earlier: To what extent does current PBRN work, as represented by this sample, continue to address questions that come from, and are best answered by, gathering data at the practice level? In large measure the work reported in this issue does indeed represent issues and questions best answered within a practicebased research context. Note, however, that I did not mention "network" in the previous sentence. Some of the work, while associated with PBRNs, occurred within practice organizations, and it is quite possible that the work could have been done without the infrastructure of the practice-based research "network." This is an important dilemma for PBRN work going forward, and it is reflected in the lack of information from any of these articles, with the exception of the commentary, on where the idea for the study originated and how practices were recruited.

Reporting on these aspects of study idea generation and practice recruitment could become standard portions of the background and methods sections of practice-based research articles. Including this information would go a long way toward building a knowledge base regarding the current impetus for practice-based research and the work required by PBRN or other infrastructures to implement practice-based studies. It is critically important that practice-based research remain relevant to our practices, answering the everyday questions that arise in the delivery of primary care. Sourcing questions and research topics from our practices is an important way to maintain the engagement and relevancy of our work. Understanding the work required to recruit practices to participate in practice-based research is also critical to being able to scope the need for PBRN infrastructure, ongoing relationships with practices, and what is required to support that infrastructure. Both of these aspects are central to understanding and maintaining the re- lationships that are so vital to practice-based research.

\section{Conclusion}

As evidenced by this issue of the $7 A B F M$, the current state of practice-based research seems to be good. Practice-based researchers are delving into topics that are relevant to primary care practices. More attention to reporting how topics are developed and practices are engaged will assist greatly in understanding the need for and maintaining the vibrance and relevance of the PBRN community.

\section{References}

1. Stephens GG. Family medicine as counterculture. Fam Med 1989;21:103-9.

2. Mullan F. White coat, clenched fist: the political education of an American physician. New York: Macmillan; 1976.

3. Becker LA, Green LA, Beaufait D, Kirk J, Froom J, Freeman WL. Use of CT scans for the investigation of headache: a report from ASPN, Part 1. J Fam Pract 1993;37:129-34.

4. Becker LA, Green LA, Beaufait D, Kirk J, Froom J, Freeman WL. Detection of intracranial tumors, subarachnoid hemorrhages, and subdural hematomas in primary care patients: a report from ASPN, Part 2.J Fam Pract 1993;37:135-41.

5. Froom J, Culpepper L, Green LA, et al. A crossnational study of acute otitis media: risk factors, severity, and treatment at initial visit. Report from the International Primary Care Network (IPCN) and the Ambulatory Sentinel Practice Network (ASPN). J Am Board Fam Pract 2001;14: 406-17.

6. Etz RS, Hahn KA, Gonzalez MM, Crabtree BF, Stange KC. Practice-based innovations: more relevant and transportable than NIH-funded studies. J Am Board Fam Med 2014;27:738-9.

7. Mader EM, Fox CH, Epling JW, et al. A practice facilitation and academic detailing intervention can improve cancer screening rates in primary care safety net clinics. J Am Board Fam Med 2016;29: $533-42$.

8. Darby-Lipman P, Aspy CB. Local learning collaboratives to improve quality for chronic kidney disease (CKD): from four regional practice-based research networks (PBRNs). J Am Board Fam Med 2016;29:543-52.

9. Johnson K, Tuzzio L, Renz A, Baldwin L-M, Parchman M. Decision-to-implement worksheet for evidence-based interventions: from the WWAMI region practice and research network. J Am Board Fam Med 2016;29:553-62. 
10. Westfall JM, Fagnan LJ, Handley M, et al. Practicebased research is community engagement. J Am Board Fam Med. 2009;22:423-7.

11. Rapp RC, Pascoe J. Clarifying parents' and pediatricians' views of partnership. J Am Board Fam Med 2016;29:563-71.

12. Cole AM, Keppel GA, Andrilla HA, et al. Primary care patients' willingness to participate in comprehensive weight loss programs: from the WWAMI Region Practice and Research Network. J Am Board Fam Med 2016;29:572-80.

13. Careyva B, Shaak K, Mills G, et al. Implementation of technology-based patient engagement strategies within practice-based research networks. J Am Board Fam Med 2016;29:581-91.

14. Wallace LS, Angier H, Huguet N, et al. Patterns of electronic portal use among vulnerable patients in a nationwide practice-based research network: from the OCHIN practice-based research network (PBRN). J Am Board Fam Med 2016;29:592-603.
15. Litvin CB, Hyer JM, Ornstein SM. Use of clinical decision support to improve primary care identification and management of chronic kidney disease (CKD). J Am Board Fam Med 2016;29:604-12.

16. Dexter E, Fields S, Rdesinski RE, Sachdeva B, Yamashita D, Marino M. Patient-provider communication: does electronic messaging reduce incoming telephone calls? J Am Board Fam Med 2016;29:613-9.

17. Chung CF, Munson SA, Thompson MJ, et al. Implementation of a new kiosk technology for blood pressure management in a family medicine clinic: from the WWAMI Region Practice and Research Network. J Am Board Fam Med 2016; 29:620-9.

18. Gaglioti AH, Werner JJ, Rust G, Fagnan LJ, Neale AV. Practice-based research networks (PBRNs) bridging the gaps between communities, funders, and policymakers. J Am Board Fam Med 2016;29: 630-5. 